\title{
Interactive comment on "Inorganic carbon fluxes on the Mackenzie Shelf of the Beaufort Sea" by Jacoba Mol et al.
}

\section{Jacoba Mol et al.}

jacoba.mol@dal.ca

Received and published: 8 November 2017

The authors wish to thank referee \#2 for their insightful comments and helpful revisions of this manuscript. Each of the referee's comments are individually addressed below, with the comment first listed and then responded to.

1) The manuscript becomes poorly organized starting with the results. Some of what is reported in there (e.g. Wind Forcing 3.3) should probably go in a background section.

As this comment suggests a background section could be introduced, taking some of the results including the wind forcing and possibly water mass composition. Reorganizing these sections somewhat was considered, but ultimately left this way as a choice of style. 
2) Pg. 2, L 16. The comment that, " $\mathrm{N}$ flux from the MacKenzie has little impact on NPP" should be cited.

Can be cited from the Tremblay et al., 2014 paper.

3) Pg. 2, L 16. What happens to DON/PON? Is it totally refractory? A citation would help

The authors mention this nitrogen dynamics only as a way to highlight the importance of upwelling for this shelf region with high river input. Since there is no actual mention of nutrient levels in the results or discussion, this section of the introduction was limited. It is possible to expand more on these nutrient dynamics, but seems somewhat unimportant to the main findings of the paper.

4) Pg 6 L10-15. A diagram would be useful for the reader.

As mentioned in reviewer 1's comments, a diagram can be added to Figure 1 to help clarify.

5) Pg 6 "Calculation uncertainty": Please clarify measurement uncertainty and methods. It's confusing. Where exactly did the standard deviations come from? How do you know the sensor or instrument errors? Also your approach requires that the errors be normally distributed. Is this the case?

We can change this paragraph to add more description of methods for finding the uncertainty. For this purpose, I believe we can assume that the errors are normally distributed. The effect of the errors of temperature, salinity and DIC are very small and do not give an uncertainty that is near the significance of the estimated transport. Most of the uncertainty comes from the model and this is the best way that we have seen fit to estimate the error coming from the ANHA4 model. "Uncertainty was estimated using Monte Carlo simulations for the calculation of cross-shelf mass transports. The inputs for the simulations were randomly generated from normal distributions, and 1000 points were chosen randomly for each of the variables. Standard deviation for salinity

Printer-friendly version

Discussion paper 
(+/- 0.0003) and temperature (+/- $0.001 \mathrm{deg} C)$ were taken from error calculations with the Seabird SBE 911 plus CTD sensor, and standard deviations for DIC measurements $(+/-2 \mathrm{umol} / \mathrm{kg})$ were taken directly from repeat measurements of sample and standard measurements using the VINDTA 3C. The error of the modelled velocity was estimated by taking the standard deviation of the velocity at each station and depth layer from the ANHA4 model over the two-month study period."

6) Advertise your main findings in the abstract and quantify them in the conclusions. A casual reader will not get the results of your efforts.

The authors agree that the abstract and conclusion can be altered to more clearly address findings.

Abstract: P1L16: "A strong upwelling event prior to sampling on the Mackenzie Shelf took place, with high pCO2 water from the upper halocline layer (UHL) being moved onto the shelf bottom, with a maximum on-shelf DIC flux of $16.9 \times 103 \mathrm{~mol} \mathrm{C} \mathrm{d-1}$ $\mathrm{m}-2$ during the event. The total on-shelf transport of carbon through the upwelling event was found to be $65+/-15 \times 10-3 \mathrm{Tg} \mathrm{C} \mathrm{d}-1$. TA and the oxygen isotope ratio of water $(\delta 180)$ are used to examine water-mass distributions in the study area and to investigate the influence of Pacific Water, Mackenzie River freshwater, and sea-ice melt on carbon dynamics and air-sea fluxes of carbon dioxide (CO2) in the surface mixed layer. Understanding carbon transfer in this seasonally dynamic environment is key to quantify the importance of Arctic shelf regions to the global carbon cycle and provide a basis for understanding how it will respond to the aforementioned climate induced changes."

Conclusion: P15L4: "Carbonate system parameters were measured in the Beaufort Sea during August and September of 2014. The cross-shelf transport of inorganic carbon during an upwelling event was estimated using the velocity fields from output of the ANHA4 simulation. This upwelling period from August 16th to 20th displayed an off-shelf transport in the surface layer of $14+/-3 \times 10-3 \mathrm{Tg} \mathrm{C} \mathrm{d-1}$ and a corresponding

Printer-friendly version

Discussion paper 
on-shelf transport in the subsurface of $65+/-15 \times 10-3 \mathrm{Tg} \mathrm{C} \mathrm{d-1,} \mathrm{bringing} \mathrm{water} \mathrm{from}$ the UHL onto the shelf. This upwelled UHL water alters the carbonate chemistry of bottom waters and poses a potential threat to calcifying organisms due to the high DIC:TA ratio ( $>0.975$ ) present. Upwelling of this water with $\mathrm{pCO} 2$ concentrations $>$ 600 uatm could change the net flux of $\mathrm{CO} 2$ across the air-sea interface over the shelf, with possible outgassing of $\mathrm{CO} 2$ or a suppression of the uptake of $\mathrm{CO} 2$. The mean circulation through the two study months showed upwelling to be the dominant process, but changes in circulation seem to be common in this region, with both estuarine and anti-estuarine dynamics taking place."

7) Several other edits picked up by reviewer 1 definitely need to be addressed.

See comments on reviewer 1's edits.

Interactive comment on Biogeosciences Discuss., https://doi.org/10.5194/bg-2017-318, 2017. 